"The Roles of U-Matic vs. Beta vs. VHS- Consideration for Educational Technologists"

\title{
Steve Kanaba
}

So you've made the decision to go video. You're interested in utilizing videocassettes, but one question keeps coming up: which format should I go with? This question is further complicated by a flood of recorders and players marketed by well over a dozen manufacturers. Let's take a look into the not too distant past and recall the reasons for the proliferation of the three currently popular videocassette formats.

Video recording techniques have been around since 1956. The search for economical, high quality video reproduction yielded many different approaches. Some standardization attempts were made, but it was not until 1972 that SONY introduced a simple and practical solution to a low cost video recorder/player that could be operated with a minimal amount of training. The $3 / 4$-inch "U-matic" videocassette was the first successful inter-manufacturer standard.

The 3/4-inch U-matic recorder/player was originally supposed to be marketed for home use at a retail price of two-to-three hundred dollars. However, the Japanese had not yet developed the machine and tape technologies to reach this target. By the time it was released, the 3/4-inch U-matic was carrying a price tag of over $\$ 1000$ and was marketed, not to the consumer, but to the industrial and educational user. Yet, interest in the consumer market remained: it was too vast-a market to be ignored. Development continued.

A problem soon presented itself: How to cut tape consumption( and the resulting cost) without effecting sound and picure quality. The solution was to develop a tape cassette and machine capable of recording the greatest amount of information in the least amount of space. Both cassette and machine would have to be packaged in a small and efficient size.

Resourceful Japanese engineers developed a method of high density recording that allows more signal information to be put down than is possible with conventional techniques. The "guard bands" which separate the video tracks were eliminated by setting the tracks at an angle to each other. This technique, termed "azimuth" recording, allows the recording of video information in a much denser configuration (see diagram \#1). Here, then is where the real difference between the three formats begins. 3/4-inch rcordings uses conventional helical scan techniques, whereas VHS and Beta records each video track alongside another, but as a slightly opposite slant. In Beta format, the slant is seven degrees. In the VHS machine, the slant is six degrees.

The second and most obvious difference between the three formats is their loading designs (see diagram \#2). 3/4-inch (U-matic machines use the U-load, which requires a complicated mechanical system, and subjects the tape to a great deal of wear, thus shortening its life. The B-load on Beta machines is an improvement on the U-load, but still requires 
more compuicated mechanics than the M-load used in VHS machines. The M-load provides a shorter tape path, quicker threading, and less tape stress. Other differences include the speed at which the tape passes over the head, and the size of the video head drums.

Since all of these technical details add up to the obvious incompatability between formats, how do you judge which is best for your application?

If mastering and editing are consideration, the 3/4-inch U-matic format is by far the most advanced of the videocassette formats. Editing capabilities include assemble and inserts of video and audio on two channels. It is still one of the most cost effective hardware systems in a non-broadcast setting. Instituional programs originated and edited on 3/4-inch machines yield highly acceptable results and require a minimum of operator training. Since tape costs are much higher in the $3 / 4$-inch format, many users record and edit programs on \#-inch and make copies on Beta and/or VHS for distribution. The latter offers significant savings in tape stock and a lesser weight and size allows for savings in postage. These two considerations alone can influence your decision if you anticipate a high volume of distribution. If bi-lingual audio capabilities are important, the 3/4-inch format wins again. All 3/4-inch recorders are capable of two channels of audio, while only some industrial models of Beta and VHS offer two channels of audio.

Duplication of tapes is possible to and from any of the three formats, i.e., 3/4-inch to Beta or VHS; VHS to 3/4-inch or Beta; and Beta to $3 / 4$-inch or VHS. Interconnecting player to recorder is a simple procedure, but one should seek and obtain permission to reproduce copywritten material. Beyond the ethical considerations of duplicating tapes, it is important to realize that international exchange of tapes requires some knowledge of world standards. Whereas 3/4-inch U-matic, VHS and Beta refer to three different electro-mechanical devices for recording and playing a video signal, there also different ways of gnerating a video signal. The three world standards (NTSC PAL, and SECAM) apply to the engineering techniques in which the video signal is created. Since the NTSC system is used throughout North America, it is impossibe to receive or record a PAL or SECAN signal. Many major cities offer services to convert PAL and SECAN to NTSC signals which, in turn can be recorded on any format recorder i.e., Beta, VHS, or 3/4-inch U-matic. It should be mentioned here that both Sony and NEC offer 3/4-inch machines that can playback PAL/SECAM/NTSC signals (NEC model \# PVC-9277; Sony model \# VP-2030) and record the same (NEC model \# VO-2630). The educational technologists has indeed many considerations when selecting the proper hardware to fit his video needs.

There are many options and features offered by different manufacturers and distributors. In many ways, there are few differences between the consumer VHS and Beta machines and their industrial versions. Simularly, there are "broadcast" versions of many $3 / 4$-inch machines. The cost of and standard 3/4-inch machines. Playback picture quality, on the other these machines are generallv higher than consumer VHS or Beta models 
hand, is better on the more expensive models, due, in part to the fact that some manufacturers use brushless dc motors and a direct drive video head cylinder which eliminates most of the belts and reduces slippage and jitter, increasing picture stability. Industrial and broadcast models also include an internal capstan servo system which can be modified to lock to an external video signal for use with a time base corrector. These models also have BNC type connectors for video and either LR or phono type connectors for audio.

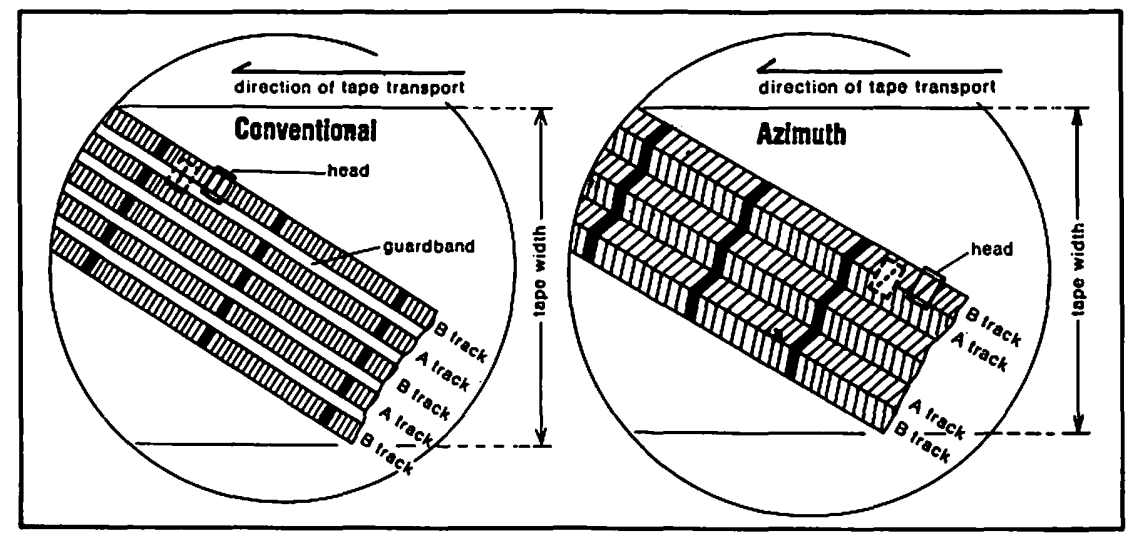

Loading Design

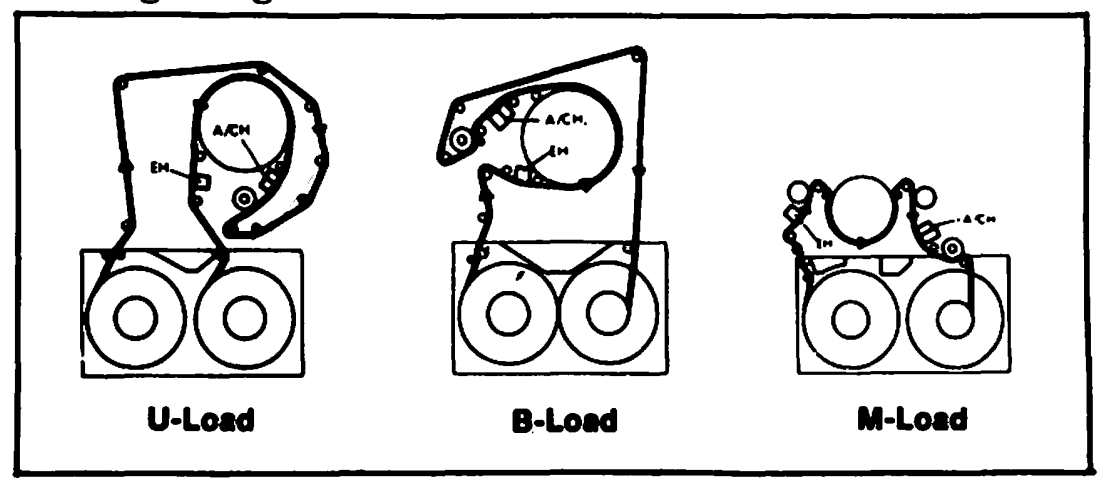

There are many other features to look for when specifying hardware. Still frame capability allows the user to stop the tape at a particular point in the tape and examine a frame of video. Solenoid activated controls make remote control a possibility. Search functions, random access capability, internal turners, programable timers, variable record and playback speeds all warrant consideration. Recording times in the industrial Beta and VHS machines are usually less than in the home versions. $3 / 4$-inch machines are limited to one hour maximum recording time although the Sony LVO-7000 allows for either one or two hour recording and playback. DuPont also offers long play-record U-matic tape stock in 75 and 90 minute versions. The Betamax industrial machines are limited to one hour and the VHS industrial machines to two hours, (with the exception 
of the Panasonic NV-1000A which can record in the four-hour mode). The reason is that better picture and sound quality is gained at the standard speeds and is usually more important to the professional user. It is also important to realize that tapes recorded at long play and super long play (in VHS) and $X^{2}$, and $X^{3}$ (in Beta) sometimes will not playback well on a different machine. It is recommended therefore, to record tapes at standard speed if you anticipate good tape interchange.

Since the $3 / 4$-inch $U$-matic format has been in use longer (especially by educational and industrial users) there are many more selections available in this format. On the other hand, the majority of pre-recorded entertainment tapes are available in both VHS and Beta. Polls show that the VHS tapes outsell the Beta tapes. This is probably due to the greater number of VHS machines available.

And still the question remains: Which of the three formats should I consider? Before you consider your hardware, it would be best to determine your needs and apply the hardware with the features to fit thost needs. Beyond these considerations, find out whether:

1. Are there qualified people available to service and repair the equipment?

2. Are parts readily available?

3. Are loaner machines available while my machine is down?

4. Are blank tapes of a compatible format available in my area? Can they be obtained on short notice? Are they reasonably priced?

Your decision will depend on what equipment, services, and cost facotrs will give you a package that suits your preesent needs as well as your plans for the future.

Steve Kanaba
Media People
7117 East Camelback
Scottsdale, AZ 85251
$(602) 941-8701$

Vido/film AV/Photo Training Consulting

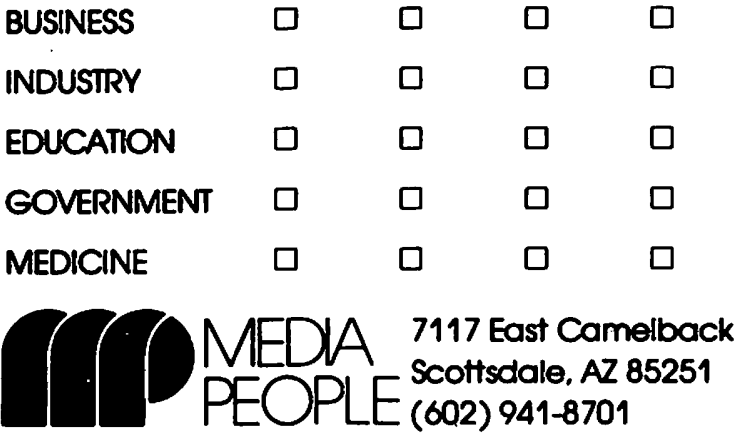

